\title{
Of Mice and (Wo)Men: Tampons, Menstruation, and Testing
}

\author{
Sharra L. Vostral
}

The tampon, a uniquely gendered technology to absorb menstrual fluid, has a long history of use and modification during the twentieth century. The familiar cotton, but also rayon, silk, polyester, and even hydrophilic salts have been used at one point or another. By 1980, 70\% of women in the United States used tampons during their fertile years to absorb their menses (Okie 1981). Women still rely on them to contain a bodily fluid in an American society where the norm is to keep it hidden (Vostral 2008). Tampons have come to belong to a liberation toolbox, providing a means for physical mobility and bodily freedom in a society where menstruation has neither been privileged nor celebrated. What is less recognized is that women's bodily experiences with tampons are directly linked to developments in material science, corporate research, and gynecological observations about menstrual cycles. In the face of multiple variables, how did researchers devise tests to improve designs while keeping an eye on women's health?

The practical work of tampon testing has been predicated upon broad cultural conditions: prevailing ideas about women's bodies, notions about physiological and cultural gender differences, and concepts of the role of science and medicine in optimizing progress and well-being in the United States. I argue that to capture these conditions, the relationship of tampons to testing and to women's bodies is best seen as a three-way recursive loop (Fig. 50.1). However, in this loop women's bodies must be instrumentalized and subjected to a scientific rationality, which is no easy task methodologically. Sometimes women are "the right tool for the job," to borrow from Adele Clarke and Joan Fujimura, and sometimes they are not (1992). Seen through the lens of socially informed cultural analysis, it is also 
Fig. 50.1 The recursive loop of testing (Credit:

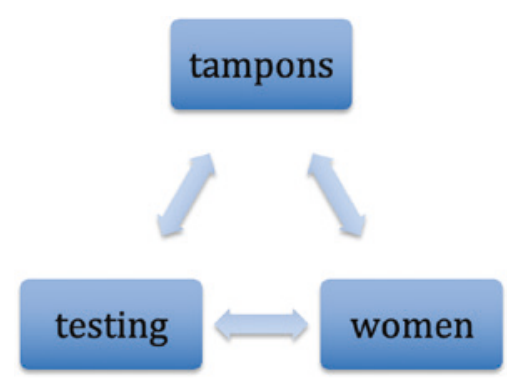

politically problematic to strip away agency and humanity in the name of collecting data for the purposes of science and evidence-based medicine.

The pressures to collect empirical data through experimentation furthered a scientization of menstruation, which began late in the nineteenth century (Vostral 2008; Hasson 2012). Patterns of social power and privilege configured this science, with evidence taking different forms and shapes during the twentieth century. For example, during the 1920s, ideas about scientific management informed data collection about sanitary napkin distribution and use, while the 1980s witnessed tightly controlled laboratory conditions to simulate vaginal anatomy and tampon absorption. Ideas of efficacy and safety also shifted depending on notions of corporate responsibility and market opportunity in a given setting or era. The conditions under which menstrual technologies emerged and perished on the American market varied on many levels.

In this essay, I divide approaches to the material testing of tampons into three major categories: (1) cultivating women test subjects; (2) medicalizing tampons; (3) measuring for safety. The first section demonstrates how women test subjects held a prominent role in the generation of empirical data from the 1920s to the 1950s. The inclusion of women in systematic "field" trials of industrial products marked a radical departure from the use of anecdotes and hearsay to improve sanitary napkins. The medicalization of tampons, discussed in section two, demonstrates how by mid-century, medical models gained traction and some physicians emerged to offer evidence for tampon safety. Nurses and gynecologists became the mouthpieces of assurance and helped to allay fears as well as endorse the efficacy of tampons. Part three focuses upon new measurements for safety, ushered in with formalized Food \& Drug Administration (FDA) regulations set in place in the late twentieth century for measuring and assessing tampons as medical devices. However, the testing often failed to predict imminent health hazards, such as Toxic Shock Syndrome (TSS) associated with superabsorbent tampons. Design modifications to tampons, changes in material composition, and the cultivation of women test subjects exposed assumptions in scientific and medical practice, ideas about safety, and attitudes concerning gendered and menstruating bodies. 


\section{Humans as Test Subjects}

In order to appreciate the contours of how tampons have been tested, it is important to acknowledge the context of Western-style medicine that rose to acceptance during the late nineteenth and early twentieth centuries. Medicine began to incorporate scientific practices and methods into the assessment of treatments and surgeries. Some of these treatments were perceived as harmless despite their consequences, with efficacy figuring as the central concern for the analysts, while others raised serious concerns about the ethics of the very practices (Lederer 1997). There is a growing body of literature addressing this unsavory side of medicine in which imprisoned and institutionalized men and women, orphans, and disadvantaged "others" became the objects of questionable medical experimentation, conducted usually without their consent (Goodman 2008; Hornblum 1999). Changes in the mid-to-late twentieth century in human subjects testing guidelines, institutional research board (IRB) review, and informed consent are certainly improvements, though problems still remain (Epstein 2009; Wailoo 2008; Braun 2005).

Tampons, however, provide a case for examining not only the role of human test subjects, but also how researcher and subject gender identities influence the ways that testing is constructed and implemented. The gender identity of the person creating this technology begins to reveal itself as central to the details of scientific development, and starkly so. The tampon was seen by researchers as a female-specific technology that could not reasonably be tested upon men, meaning that any effort at reaching associative results was not seen to be scientifically valid. Here, women are seen as different from the ideal white male test subject. Unlike cosmetics that were tested on male prisoners (Hornblum 1999), tampons were not, and scientists were hard pressed to imagine a male body correlate to the cervix and vagina during menstruation. On the sliding scale of gender difference, testing tampons on men crossed an imaginary binary, and the decoupling of menstruation from the category of women had not yet been conceptualized with the term "menstruators" (Bobel 2010).

As such, male scientists could not "self-experiment" as had been the practice for so many in the past. The simple taste test in chemistry determining sour acids from bitter bases demonstrates one level of this first-person knowledge. Rebecca Herzig outlines the gruesome ways that scientists offered their own bodies and well-being for the pursuit of knowledge and information, particularly in the area of x-ray experimentation (Herzig 2001, 2005). In part, this ability to self-experiment relied on a level of personal agency and decision-making embodied by privileged white men of the time.

The relationship of male researchers and female test subjects was often particularly laced with gendered power structures of patriarchy and paternalism. While male inventors could not sacrifice themselves, though they may have wanted to, many could request or insist that their wives volunteer as test subjects. If the male scientists did not have their own first-hand experiences, 
sensations, and feelings with tampons to rely upon as trustworthy data, wives were their proxies. This opens up an interesting window into their marriages with wives seeming to be not only complicit but also active proponents of the designers' patents. Years invested in marriage and the familiarity offered by that relationship provided a trusted interpreter for some scientists' first-person observations. Though the patents do not mention these collaborations, other sources do, and the invisible wives did indeed have a say in how the menstrual management technologies emerged. Not only were wives drafted into the service of science, but other nearby women including secretaries, receptionists, and relatives also served as testers of new menstrual products.

\section{Cultivating Female Test Subjects}

The first person to give serious attention to women users of sanitary napkins was Lillian Gilbreth, who deployed the scientific method in creating a hypothesis and collecting statistically significant data along with qualitative responses to interviews and surveys. Known simply as "Report of Lillian Gilbreth, January 1, 1927," it was the first to examine the entire market and pose recommendations about sanitary napkins and their use, design, and advertising. Well known for her work with husband Frank on time-motion studies, Gilbreth set out to continue the couple's work after Frank's death in 1924 (Lillian passed away years later in 1972), only to find that as a woman she was tracked by her clientele to study "feminine" things. Yet, Gilbreth was also deeply concerned with improving the quality of women's everyday lives, serving on committees under nearly every president from Hoover to Kennedy, consulting about women's labor, women in defense services, and even the Girl Scouts. Establishing her own credentials within that constrained field, however, she landed one of her first big accounts with Johnson \& Johnson, who sorely needed advice about women's feminine hygiene practices, as they were called. Kotex's 75\% market share walloped Johnson \& Johnson's Nupak, which held only $2 \%$. With gusto, she dove into the study of sanitary napkins and provided a searing and revealing report to R. W. Johnson.

Gilbreth and her two female staff members conducted a multipronged study about the state of sanitary pads, contemporary products on the market, their effectiveness, and women's wants (Gilbreth 1927; Fouché and Vostral 2011). She interviewed educators, deans, and instructors teaching health and hygiene classes to ascertain their opinions about the design and materials for active young women; her staff conducted interviews and sent out surveys to more than 3000 women about their menstrual hygiene use; finally, her team studied the characteristics, strengths, and flaws of $\mathbf{5 3}$ different sanitary napkin brands available for purchase at the time. She was particularly blunt in her assessments of what she saw as bad branding. "L. B. Sanitary \#24: If you have 
to say sanitary, you may as well add napkin; Eagle Brand \#25: A buyer would be lucky if she got what she asked for under this name instead of cheese or baby's milk" (Gilbreth 1927, 37-44). The "S. S. Napkin" so obviously referenced the name of an imaginary boat that the staffers refrained from even commenting about the ludicrous branding.

The important thing about Gilbreth's methodology was that it was the first systematic study of women's preferences about menstrual management technologies that focused on the end users, not just the needs of the corporation. This scientific method was in stark contrast to the anecdotal evidence male scientists gleaned from letters of complaint received by customer service, and more provincially, asking their female secretaries, typists, and wives (Graham 1998). It was clear that women did not like the commercial menstrual products, and Gilbreth ascertained why. Everything from the marketing, to the sizes of the boxes, to the actual product and its materials mattered. She learned that Kotex, though still short on women's praise, held appeal because it could be modified, in the best sense of "appropriating technology" (Eglash et al. 2004). Vaseline rubbed on the corners softened the edges and improved comfort. Tabs could be cut and shortened, and even the cellucotton filler could be thinned to make it less bulky (Gilbreth 1927).

Based upon Gilbreth's detailed report, R. W. Johnson took the criticisms and made substantive changes to a new sanitary pad called Modess, a name no doubt sanctioned by Gilbreth as unobtrusive and feminine sounding, like modest. In his patent of 1929, there is no mention of Gilbreth by name, but her recommendations set forth in the report were embodied in a new sanitary pad, one based upon prototypes she tested. Importantly, her suggestion for "cut off corners" based upon women's responses emerged as "feathered edges" in the patent, reflecting a discourse of an industrial process rather than a seamstress at a home. The filling, though compared to the "soft feel of cotton," was not composed of it. Johnson instead incorporated a water repellent "cellulosic vest" to act as a barrier between the pad and an undergarment. Next, "filmated gauze" enclosed the vested pad, and Johnson also had a pending patent on that fabric: "surgical gauze the interstices and one face of which are clothed with a superficial film of free fibrous material, preferably cotton slivers" for absorption and soft texture (Johnson 1927, patent $\# 1,705,366)$. This layering also contributed to a pad with less bulk.

Though Johnson incorporated many of Gilbreth's suggestions, materialized in the patent and new product, a more prescient recommendation centered upon predicting, testing, and analyzing materials. She warned Johnson \& Johnson not to follow the trend of designing "laboratory devices for testing." In essence, Gilbreth declared limits to the utility of technology as a source of information. Machines could not so easily replicate women. Only women held the unique qualifications to test sanitary pads because they knew how they felt and how they fared. In so doing she granted the women voice, or subjective legitimacy. Real-life field tests were required, 
and moreover, should be managed by a woman researcher. She recommended that "a woman be added to the staff of Johnson and Johnson and that all products be submitted to women for inspection of design and tested for actual use." But she warned not to bother with hiring a woman with no smarts, for "an unintelligent tester would be worthless or worse because their findings might encourage the development of a poor product or discourage the development of a good one" (Gilbreth 1927, 133-34). She predicted that random testing practices and insufficient interpretation of the results from testing could yield devastating effects upon a brand and therefore a company.

As it stood, the survey generated interest in a new product. During her interviews, "questions were frequent as to when it would appear, what name it would bear, and who was manufacturing it" (Gilbreth 1927, 14). Gilbreth capitalized upon women's desires for a better sanitary napkin as an incentive to enroll them as test subjects; the only remuneration was satisfaction in the knowledge that their responses would contribute to the design of a new product. The success of the investigation was owed to Gilbreth's adept skills and survey methods in generating woman-to-woman answers and responses. Together, these female researchers contributed to a growing science of menstruation, in which their own position as scientists leveraged certain privileges but their status as women circumscribed their research. They shared an interest in the test subjects as a part of improving an essentialized understanding of "the women's experience," yet they still instrumentalized them in assessing the materiality of products and female bodies as measured by tools, thus bolstering their expertise. They provided an avenue to hear many women's voices, but it was their privilege that legitimated the stories of the test subjects.

\section{Medicalizing Tampons}

Asking women questions about their menstrual practices, and even requesting that they report back about sanitary napkin use may have been quite personal, but a new level of testing emerged when the "internal sanitary napkin"-the tampon-emerged as a viable menstrual management technology. In this new era, medical practitioners began to dominate the design and testing of the material components of tampons. No doubt because they were used vaginally, this fell to the realm of gynecologists. The expert stature brought by physicians and nurses helped to legitimate not only the concept of the tampon but its reputation for efficacy and safety. This was especially important for the younger clientele that began to use tampons, with many questioning whether or not they were threatening the virginity of pubescent girls by breaking the hymen (a task purportedly for a husband on a wedding night).

Physicians from the late nineteenth to early twentieth centuries sometimes inserted tampon-like absorbent materials into body orifices to stop bleeding, and any tampon patented between 1890 and 1921 referred solely to medical 
and surgical application (Farrell-Beck and Klosterman Kidd 1996). The notion of a specially designed, disposable tampon specifically for menstrual fluid emerged in the late 1920s and early 1930s. Earle Cleveland Haas, an osteopath, patented both a compressed cotton tampon and a telescopic applicator. His design was unique as much for the tampon composed of cotton stitched lengthwise and then compressed by old candy machines, as for the disposable cardboard telescopic applicator to deliver the tampon into the vaginal canal without women's fingers needing to touch any body parts. Rather pragmatic in his assessment, he reported that he had seen so many patients in his practice struggle with the mess of pads, he felt he could do better. He also enlisted his wife (who remained unnamed), a nurse, to wear many of the prototype tampons for his 1931 patent that later became Tampax (Bailey 1987). Through her connections, they distributed the tampons to other female colleagues, enrolling them for feedback. So convinced was he of his command of female anatomy, earned through years of medical practice, that he felt there was no need for data collection, such as measuring the size of the vaginal canal. He noted that he had "seen so damn many of them I had an idea" of the various shapes and sizes (Kehm v. Procter of Gamble 1982, 1179). Believing women had standardized anatomy, they were interchangeable.

Furthermore, he dismissed the idea of broader testing exactly because of the standardization of the vagina. He continued, "Don't make any difference where [the tampon] was in there, it would soak it up" and "I tried so many of them I knew about how much they would absorb" (Kehm v. Procter o Gamble 1982, 1179). Thus, he dispelled any need for broader testing beyond that of his wife and her opinion, so strong were his convictions and his hubris. Like many engineers of the time, even in unrelated fields such as the cement industry (Slaton 2003), he exuded confidence and arrogance about the certainty of his science, which was not even really "science" at all. This often worked to stifle naysayers and claim intellectual rights to knowledge, dismissing critique and bluntly asserting scientific superiority. Once Haas received his patents, he sold them to Gertrude Tenderich for $\$ 32,000$ and it was she who marketed and developed the Tampax branding and founded Tambrands corporation (Kehm v. Procter \& Gamble 1982). Tenderich, however, made sure to include Haas in her marketing by making claims that a physician designed Tampax and that the Journal of the American Medical Association had accepted the new product for advertising, a claim that had no substantive value. She also advertised the tampon at medical conventions with a female X-ray technician who dressed as a nurse to further legitimate the product (Bailey 1987).

The issue of testing women's bodies for tampon efficacy, however, gained momentum during the 1940s and 1950s when empirical medical data became preferred to anecdotal or even qualitative evidence. Corporations led the way by enrolling physicians and gynecologists at medical colleges to devise trials, locate women test subjects, and manage and publish the results of the experiments. In this way, the corporations could affix supposedly 
neutral results, affirmed by objective scientific methods, to their products and garner approval for a legitimate and functional medical device. The Personal Products Corporation, a division of Johnson \& Johnson which manufactured Meds tampons, sponsored one such test. The name of Meds captured its medicinal overtones to make it sound sterile, safe, and salubrious. Irja Widenius, a physician in the Department of Obstetrics and Gynecology at Columbia University, led the study, using the cutting-edge technology of $\mathrm{X}$-rays to determine absorption capability and position of tampons in situ. This was a remarkable, and very visual, method. Instead of measuring how much water a cotton tampon might hold, or even collecting used tampons to determine their absorption capacity, she instead X-rayed women's pelvic areas while they were menstruating and wearing different brands of tampons to "see" how well they worked, and how well they were positioned to avoid leakage. "A Study of Commercially Manufactured Catamenial Tampons" (1944) was published in the American Journal of Obstetrics and Gynecology.

The main challenge that Widenius encountered was that menstrual blood and cotton tampons were not particularly suited for this sort of visualization since they were transparent when viewed with $\mathrm{X}$-rays. Widenius directed technicians to brush barium sulfate, a radiopaque powder, onto the tampons prior to the female test subjects inserting them into their vaginal canals. She took a series of before-and-after X-rays, including half an hour after insertion, to determine the ideal position of the tampons and how well they were absorbing fluids. Widenius was delighted with the results. Not only did she conclude that tampons were safe, but she addressed concerns that they might cause infertility by pointing out that of the twenty-five women who participated, five became pregnant during the study and three went on to deliver babies. Of course, with our current understanding of the dangers posed by radiation to DNA threads, and especially to sensitive reproductive organs and vulnerable fetuses, the test in retrospect is rather horrific and points to the need for safeguards delivered by institutional review board protocols. Yet, Widenius interpreted the pregnancies as data points in relation to the tampons and surmised that they did not cause infertility and were safe. By turning women's bodies into tools, she legitimated the cotton tampon, its safety, and the practice of testing itself as a means to quell cultural concerns.

\section{Measuring and Its Limitations}

From the very early days of the FDA, tampons received little attention and were classified as cosmetics, falling into a feminized category that had little to no oversight in terms of labeling, materials content, safety, or advertising claims. Because the Medical Device Amendments (MDA) of 1976 categorized tampons as Class II medical devices-products that had already been sold on the market and (in the eyes of those deciding such matters) proven safe by their track record-they did not need to undergo safety testing. Furthermore, companies could establish "substantial equivalence" for 
any new product, thus bypassing a premarket approval process at the FDA (Vostral 2018). For the most part, the design of newly patented tampons was still not substantially different from the old Tampax patent of 1931, even though new materials were incorporated. Semi-synthetics such as rayon, derived from cellulose wood pulp, found their way into the composition of tampons such as Tampax, Playtex, Kotex, and O.B. Such materials were cheaper than cotton, had a soft texture, and blended well to form a cotton/rayon plug. Tampon patents emerged during the 1960s calling for a great range of materials that could be used: hemp, silk, Dacron, polyester, nylon, acrylic fibers, viscose rayon, protein fibers, and glass fibers, to name a few (Graham et al. 1960, patent \#2,934,068). Another material such as polyacrylate, a polymer structure that forms a gel when introduced to water, seemed like a perfect medium to incorporate into tampons. The era of the "superabsorbent" tampon ushered in synthetic materials, but these additions did not trigger safety concerns because the MDA "grandfathered" their approval.

However, the assumption that synthetic materials were inert came back to haunt scientists. By the 1970s, Procter \& Gamble had begun to design, test, and market Rely, an entirely synthetic tampon devoid of cotton. Its components were synthetic: a polyester bag containing small polyester foam cubes and the thickening agent carboxymethylcellulose that formed a gel once exposed to fluid. The design was entirely innovative, and it truly absorbed more liquid than its cotton counterparts; uncomfortably so, according to many women who complained Rely dried them out, making additional tampon changes painful.

In 1978, during the time period that researchers at Procter \& Gamble were honing the final design and marketing of Rely tampons, medical researchers in Colorado were naming a new disease called TSS caused by the bacterium Staphylococcus aureus. Because TSS was first associated with children, it took extensive work by state and federal epidemiologists to establish and clarify its links to superabsorbent tampons, and furthermore, that women who had used them were suffering and dying from TSS ("Toxic-Shock Syndrome-United States" 1980; "Follow-up on Toxic-Shock SyndromeUnited States" 1980; "Follow-up on Toxic-Shock Syndrome" 1980). Findings from the Centers for Disease Control (CDC) that identified Rely as the tampon associated with the most cases of TSS precipitated its withdrawal from the market in September of 1980. Despite its very dramatic departure and the bad publicity for Procter \& Gamble, the company insisted that it had surpassed federal expectations for testing at every level, as dictated by the MDA.

Testing components separately using deliberately circumscribed procedures meant that few problems with the tampon could be detected. Individually, polyester or carboxymethylcellulose could be sterile, non-carcinogenic, and hypoallergenic. Procter \& Gamble scientists tested for toxicity, carcinogenic effects, and potential harm to fetuses by implanting polyurethane (one of the 
initial components) under animal skin. They also ran tests in animals to check for inflammation or an allergenic irritation to the vaginal tract. When the polyurethane composition became a safety concern for women in the test market of Rochester, New York, managers decided to make a switch to polyester. This polyester was tested again, fed to lab animals, and furthermore, shaped into tiny mouse tampons called pledgets that lab technicians inserted into the vaginal orifices of mice to have them wear for weeks on end (Kehm v. Procter o Gamble 1982).

The mouse substitutes, though problematic on multiple levels, were not necessarily a bad thing. The commonly held practice to use lab mice, and the metaphorical guinea pig test subject, protected humans from a wide array of toxic exposure and potential ethical abuses. Yet, one must question the usefulness of these mouse pledgets, since rodents do not menstruate or experience monthly periods. They are decidedly not similar to human women in this way. As a substitute, they seem to lack numerous commonalities, from menstrual fluid to a vaginal microbiome, which both turned out to interact with tampons. The mouse tests may have served as a functional test activity, but not a good replication of field conditions.

Both artifacts and bodies - of animals and women-were tested in different ways to gauge product efficacy during a menstrual period. Neither may have provided much sound evidence to make safety claims because of assumptions that the tampon remained inert in the vagina, and that (for a moment in suspended imagination) mouse and woman body parts were interchangeable. After the animal studies were complete, Procter \& Gamble tested Rely in women. There were 1332 women in the study, and though the results were not made public, they likely enumerated women's preferences about the tampon. In addition, based on the sample size they would not find the problem of TSS that would ultimately undermine the product. The sample size was far too small to predict TSS, when only one to 17 women out of 100,000 contracts it (USFDA 1989). They did not know to look for it and did not have a sufficient sample size to predict it.

The tests conducted by Rely's developers, which sought to analyze and control specific conditions and predict outcomes, failed in the most immediate sense because they were not constructed to account for bacterial interactions with supposedly inert materials, which was indeed a new variable with TSS. But on a broader level we might see that scientists did not find danger because they were not testing for that kind of safety hazard, and did not even think to do so. It may be an unfair expectation of them, however it is equally troubling that the synthetic materials, necessary to produce the new line of superabsorbent tampons, were deemed equivalent to cotton. Problems with vaginal sensitivity emerged and were accounted for by researchers, but not the unimaginable notion that the components would coalesce as an in vivo petri dish, turning the vagina into an incubator. 
Along with the superabsorbent materials introducing sufficient oxygen to change the vaginal canal from anaerobic to aerobic, the conditions were prime for the bacterial growth of $S$. aureus and its expression of toxins. A correlating shift in $\mathrm{pH}$ from acidic to neutral during menstruation, and a lack of the requisite antibodies to the toxin in some women, meant the conditions could turn deadly (Tierno 2001). The superabsorbent and synthetic material changes made to many tampons, and not just Rely, accelerated cases of TSS during the late 1970s and early 1980s, though Rely bore the brunt of blame. Women had unknowingly endangered their health during their periods by using synthetic and superabsorbent tampons; testing had not adequately predicted this damaging bodily harm.

In part, the trust placed into laboratory simulacrum by researchers and marketers overwhelmed findings detected in the broader environment by some state and federal epidemiologists, almost rendering them moot. Because the science could not definitively prove the chain reaction leading to tampon-associated TSS, for example, it was very difficult to regulate tampons or provide guidelines about who should use them and under what conditions. In fact, it is exactly because of the vaginal vagaries that another test came to be developed and subsequently standardized to reduce variables and instrumentalize the menstruous vagina: the syngyna (to see it in use, go to https:// youtu.be/KYXUQDzSg4o). A lab instrument composed of a glass vacuum tube, it flattened differences in women's physiology and utilized simulated menstrual fluid or saline, dyed blue no less, to measure tampon absorption.

In light of superabsorbent tampons being a cofactor in TSS, and lacking a system to label the actual gram-weight absorbency capability of tampons, the syngyna had an important place in tampon safety. Yet the syngyna, like many of these other tests, raises questions about the value of the data produced when no actual menstrual fluid was used to test the tampons (Vostral 2017,2018 ). The tools for this test had imitated and sublimated women's bodies to the point of their very expunction. At the behest of Esther Rome of the Boston Women's Health Book Collective and her involvement on the Tampon Task Force for tampon safety and labeling, Nancy Reame, a professor of nursing at the University of Michigan, ran absorption tests with the syngyna using both saline and heparinized blood (see Reame, in this volume). She discovered that superabsorbent tampons, of any brand, held more blood than saline; this meant that the standardizing process itself was not accurate, and many brands of tampons were destined to be mislabeled as less absorbent than they actually were (Vostral 2017). Furthermore, they were more dangerous exactly because they were more absorbent. Her work raises unsettling questions about the validity of data derived from simulated vaginas and laboratory menses, where women have been erased from menstruation itself. 


\section{Conclusion}

Assumptions about women as test subjects, the infallibility of testing, and the inert nature of new materials converged with tampon development during the twentieth century in the United States. Scientific intentions notwithstanding, narrowly defined tests begot narrowly defined results, which often were neither sufficiently applicable to human bodies nor particularly useful in any other knowledge-making project about the technology. In part, the testing provided a sort of ritualistic comfort that the new products were safe, further sanctified by limited approvals granted by the governing body of the FDA and the Bureau of Medical Devices. In this regulated system, the generation of data became an analgesic and a comforting routine by which trust was engendered. The data may have revealed the efficacy of a single component but by definition could not account for the complexity of the whole, and this sort of synthesis was not a strong suit of the scientific method practiced.

How both tampons and female bodies were tested to ascertain product effectiveness reveals changing ideas about menstruation, women as instrumentalized test subjects, and concerns about health and safety. Though researchers and corporate managers looked to results from lab tests to eliminate certain kinds of dangers, they were often unable to test or predict problems posed by multivariable systems and real-world conditions. However, contingency is everywhere. At some historical moments, substituting lab animals for a human vagina followed guidelines about not using human bodies for research, as per Procter \& Gamble. But at other times, as with Gilbreth, testing devices were no substitute for protocol allowing women to speak about their own bodies. With the health risk of TSS associated with tampons, further testing was necessary; measuring absorbency and devising a standard to represent tampon sizes and ranges provided important information to women. The variety of methods used to gauge efficacy shines light upon the constructions of menstrual health, women's bodies, and technologies of menstrual management, as well as how despite best efforts, evidence-based facts do not always provide the answers to practitioners' questions.

If testing is to remain a component of menstrual management technology development, the conclusion drawn from this history is to acknowledge the significant contributions of thoughtful women researchers participating in the scientific process. This is not to essentialize their knowledge, but to show how women's menstrual experiences inform the science. From Lillian Gilbreth insisting upon a "woman's experience" to Nancy Reame using empirical evidence to argue for a feminist science methodology in tampon absorption tests, women's voices and feminist approaches matter in cultivating better and more rigorous evidence about the safety of menstrual management technologies. 


\section{REFERENCES}

Bailey, Richard. 1987. "Small Wonder: How Tambrands Began, Prospered and Grew." Tambrands Inc.

Bobel, Chris. 2010. New Blood: Third-Wave Feminism and the Politics of Menstruation. New Brunswick: Rutgers University Press.

Braun, Lundy. 2005. "Spirometry, Measurement, and Race in the Nineteenth Century." Journal of the History of Medicine Allied Science 60 (2): 135-69.

Clarke, Adele, and Joan Fujimura, eds. 1992. The Right Tools for the Job: At Work in Twentieth-Century Life Sciences. Princeton: Princeton University Press.

Eglash, Ron, Jennifer Croissant, Giovann Di Chiro, and Rayvon Fouché. 2004. Appropriating Technology: Vernacular Science and Social Power. Minneapolis: University of Minnesota Press.

Epstein, Steven. 2009. Inclusion: The Politics of Difference in Medical Research. Chicago: University of Chicago Press.

Farrell-Beck, Jane, and Laura Klosterman Kidd. 1996. "The Roles of Health Professionals in the Development and Dissemination of Women's Sanitary Products, 1880-1940." The Journal of the History of Medicine and Allied Sciences 51 (July): 325-52.

"Follow-up on Toxic-Shock Syndrome." 1980. MMWR 29, no. 37 (September 19): $441-45$.

"Follow-up on Toxic-Shock Syndrome-United States." 1980. MMWR 29, no. 25 (June 27): 297-99.

Fouché, Rayvon, and Sharra Vostral. 2011. "'Selling' Women: Lillian Gilbreth, Gender Translation, and Intellectual Property." Journal of Gender, Social Policy and the Law 19 (3): 825-50.

Gilbreth, Lillian. 1927. "Report of Gilbreth, Inc., January 1, 1927.” Papers of Frank and Lillian Gilbreth, Special Collections Purdue University, N-File, Box 95.

Goodman, Jordan, ed. 2008. Useful Bodies: Humans in Service of Medical Science in the 20th Century. Baltimore: The Johns Hopkins University Press.

Graham, George C., et al. 1960. United States Patent Office, 2,934,068, April 26, 1960.

Graham, Laurel. 1998. Managing on Her Own: Dr. Lillian Gilbreth and Women's Work in the Interwar Era. Norcross, Georgia: Engineering \& Management Press.

Hasson, Katie Ann. 2012. "From Bodies to Lives, Complainers to Consumers: Measuring Menstrual Excess.” Social Science \& Medicine 75 (10): 1729-36.

Herzig, Rebecca. 2001. "In the Name of Science: Suffering, Sacrifice, and the Formation of American Roentgenology." American Quarterly 53 (4): 563-89.

- 2005. Suffering for Science: Reasons and Sacrifice in Modern America. Piscataway: Rutgers University Press, 2005.

Hornblum, Allen M. 1999. Acres of Skin: Human Experiments at Holmesburg Prison. New York: Routledge.

Johnson, R. W. 1927. United States Patent Office, 1,705,366, May 24, 1927.

Lederer, Susan. 1997. Subjected to Science: Human Experimentation in America before the Second World War. Baltimore: The Johns Hopkins University Press.

Michael L. Kehm v. Procter \& Gamble. 1982. United States Courthouse, Cedar Rapids, Iowa. 
Okie, Susan. 1981. "Toxic-Shock Syndrome Cases Show Decline." Washington Post, May 26, 1981.

Slaton, Amy. 2003. Reinforced Concrete and the Modernization of American Building, 1900-1930. Baltimore: Johns Hopkins University Press.

Tierno, Philip. 2001. The Secret Life of Germs: Observations and Lessons from a Microbe Hunter. New York: Atria Books.

“Toxic-Shock Syndrome-United States." 1980. MMWR 29, no. 20 (May 23): 229-30.

US Food and Drug Administration. 1989. Labeling for Menstrual Tampons [21 CFR Part 801, Section 801.430]. Federal Register 54: 43771.

Vostral, Sharra. 2008. Under Wraps: A History of Menstrual Hygiene Technology. Lanham: Lexington Books.

- 2017. "Toxic Shock Syndrome, Tampon Absorbency, and Feminist Science." Catalyst: Feminism, Theory, Technoscience 3 (1): 1-30.

- 2018. Toxic Shock: A Social History. New York: New York University Press.

Wailoo, Keith. 2008. The Troubled Dream of Genetic Medicine: Ethnicity and Innovation in Tay-Sachs, Cystic Fibrosis, and Sickle Cell Disease. Baltimore: The Johns Hopkins University Press.

Open Access This chapter is licensed under the terms of the Creative Commons Attribution 4.0 International License (http://creativecommons.org/licenses/ by/4.0/), which permits use, sharing, adaptation, distribution and reproduction in any medium or format, as long as you give appropriate credit to the original author(s) and the source, provide a link to the Creative Commons license and indicate if changes were made.

The images or other third party material in this chapter are included in the chapter's Creative Commons license, unless indicated otherwise in a credit line to the material. If material is not included in the chapter's Creative Commons license and your intended use is not permitted by statutory regulation or exceeds the permitted use, you will need to obtain permission directly from the copyright holder.

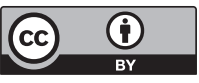

